\title{
The Externalities of Inequality: Fear of Crime and Preferences for Redistribution in Western Europe
}

\author{
David Rueda University of Oxford \\ Daniel Stegmueller University of Mannheim
}

\begin{abstract}
Why is the difference in redistribution preferences between the rich and the poor high in some countries and low in others? In this article, we argue that it has a lot to do with the rich and very little to do with the poor. We contend that while there is a general relative income effect on redistribution preferences, the preferences of the rich are highly dependent on the macrolevel of inequality. The reason for this effect is not related to immediate tax and transfer considerations but to a negative externality of inequality: crime. We will show that the rich in more unequal regions in Western Europe are more supportive of redistribution than the rich in more equal regions because of their concern with crime. In making these distinctions between the poor and the rich, the arguments in this article challenge some influential approaches to the politics of inequality.
\end{abstract}

 he relationship between income inequality and redistribution preferences is a hotly contested topic in the literature on the comparative political economy of industrialized democracies. While some authors maintain that the poor have higher redistribution preferences than the rich (Finseraas 2009; Page and Jacobs 2009; Shayo 2009), others argue that there may not be a negative association between income and redistribution (Alesina and Glaeser 2004, 57-60; Fehr and Schmidt 2006; Moene and Wallerstein 2001).

If we were to look at the preferences of the rich and poor in different Western European regions, as we do below, we would observe very significant differences in how apart the rich are from the poor regarding their favored levels of redistribution. These important differences in support for redistribution have received little attention in the existing scholarship, and yet they are a most significant element in explanations of outcomes as diverse (and as important) as the generosity of the welfare state, political polarization, varieties of capitalism, and so on.

In this article, we show that even after accounting for material self-interest, there is still a great degree of variation in redistribution preferences. We argue that this variation has to do with the preferences of the rich (and not those of the poor) and that they can be explained by taking into account the negative externalities of inequality, namely, the relationship between macro inequality and crime. Using comparative survey data, we present a set of empirical tests that support our hypotheses (and provide limited evidence in favor of alternative explanations).

The arguments in this article challenge some influential approaches to the politics of inequality. These range from those contending that second-dimension issues (particularly cultural and social ones) outweigh economic ones to those emphasizing insurance concerns, social affinity, or prospects of upward mobility. We will

David Rueda is Professor of Comparative Politics in the Department of Politics and International Relations, Oxford University, and Professorial Fellow, Nuffield College (david.rueda@politics.ox.ac.uk). Daniel Stegmueller is Professor at the Graduate School of Social and Economic Sciences, University of Mannheim (mail@daniel-stegmueller.com).

The authors share equal responsibility for the contents of this article. The order of author names is alphabetic. Previous versions of this article were presented at the Annual Meeting of the Midwest Political Science Association (2013), the Workshop on "Institutions in Context: Free Markets" (University of Tampere), the Leitner Political Economy Seminar (Yale University), the Political Economy Seminar Series (The Hertie School of Governance), the 2nd Warwick Political Economy Conference (Warwick in Venice), the Department of Government (University of Texas at Austin), and the Department of Political Science and Government (Aarhus University). In addition to the participants in these meetings, we would like to thank Jim Alt, Larry Bartels, Michael Becher, Pablo Beramendi, Charlotte Cavaille, Matt Dimick, Raymond Duch, Thomas Gschwend, Peter Hall, Torben Iversen, Mark Kayser, Desmond King, Johannes Lindvall, Isabela Mares, Yotam Margalit, Jonas Pontusson, Philipp Rehm, David Soskice, Susan Stokes, Richard Traunmueller, and Vera Troeger, as well as five anonymous reviewers and Bill Jacoby, for their comments and suggestions. David Rueda thanks the National Research Foundation of Korea for partial support of this research (grant number: 2014S1A3A2044032). Data and replication code are available in the AJPS Data Archive on Dataverse (http://dx.doi.org/10.7910/DVN/29636) and at the authors' website.

American Journal of Political Science, Vol. 60, No. 2, April 2016, Pp. 472-489

(C)2015, Midwest Political Science Association

DOI: $10.1111 /$ ajps.12212 
elaborate on our differences from these approaches in the pages that follow.

\section{The Argument}

This article's theoretical argument makes three distinct points about the formation of preferences for redistribution. The first one relates to the idea that the level of redistribution preferred by a given individual is fundamentally a function of current income. The second point distinguishes between current tax and transfer considerations and externality-related motivations, and it maintains these motivations are long term and low stakes. As such, they matter most to the rich. We will argue that, if we accept that the influence of current tax and transfer considerations is sufficiently captured by the micro effect of relative income, macrolevels of inequality will matter to the rich — and only to the rich - because of negative externality reasons. Our third point proposes that the macro effect of inequality can be explained by different microfactors and contends that the most important of these is concern for crime, as a most visible negative externality of inequality.

\section{Current Tax and Transfer Considerations}

Most political economy arguments start from the assumption that an individual's position in the income distribution determines her preferences for redistribution. The most popular version of this approach is the theoretical model proposed by Romer (1975) and developed by Meltzer and Richard (1981). To recapitulate very briefly, the Romer-Meltzer-Richard (RMR) model assumes that the preferences of the median voter determine government policy and that the median voter seeks to maximize current income. If there are no deadweight costs to redistribution, all voters with incomes below the mean maximize their utility by imposing a $100 \%$ tax rate. Conversely, all voters with incomes above the mean prefer a tax rate of zero.

When there are distortionary costs to taxation, the RMR model implies that, by increasing the distance between the median and the mean incomes, more inequality should be associated with more redistribution. The consensus in the comparative literature on this topic, however, seems to be that either there is no association between market income inequality and redistribution or, contrary to the prediction of the RMR model, less market inequality is associated with more redistribution (Alesina and Glaeser 2004; Gouveia and Masia 1998; Iversen and
Soskice 2009; Lindert 1996; Moene and Wallerstein 2001; Rodriguez 1999, 183).

These findings must be considered with a degree of caution. This is because most of this literature relies on macrocomparative empirical analyses (with redistribution as the dependent variable) and does not pay much attention to individual preferences. ${ }^{1}$ When looking at individual data, in fact, there is some support for the argument that relative income influences preferences. Using comparative data, a relative income effect is found in, among others, Bean and Papadakis (1998), Finseraas (2009), and Shayo (2009). Using American data, Gilens (2005), McCarty, Poole, and Rosenthal (2008), and Page and Jacobs (2009), again, among others, find similar effects.

It is important to point out that we emphasize income should affect preferences for redistribution across the entire income distribution. We argue that the intensity of redistribution preferences increases with distance from the mean, that is, an individual in, say, the 10th percentile of the income distribution benefits more from the RMR redistributive scheme (lump-sum payments financed by a linear income tax) than an individual in the 30th percentile. As a result, we expect the former individual to have stronger preferences for redistribution than the latter. Note that in this article, we follow most of the current literature and define redistribution as taxes and transfers and income as present-day income. ${ }^{2}$

\section{Externality-Related Motivations}

The possibility that motivations unrelated to current tax and transfer may influence redistribution preferences has received increasing amounts of attention in the recent

${ }^{1}$ Even the macrocomparative conclusion is less unambiguous than the consensus in the literature suggests. Milanovic (2000) and Kenworthy and Pontusson (2005) show that rising inequality tends to be consistently associated with more redistribution within countries.

${ }^{2}$ Put another way, we exclude arguments based on intertemporal perspectives. In the words of Alesina and Giuliano, "economists traditionally assume that individuals have preferences defined over their lifetime consumption (income) and maximize their utility under a set of constraints" $(2011,93)$. Because of the potential to define economic material self-interest intertemporally (as lifetime consumption/income), this approach opens the door to arguments about social insurance and risk (Iversen and Soskice 2001; Mares 2003; Moene and Wallerstein 2003; Rehm 2009) and about social mobility and life-cycle profiles (Alesina and Giuliano 2011; Benabou and Ok 2001; Haider and Solon 2006). We will explore some of the implications of defining economic self-interest intertemporally in the empirical analysis below (as robustness checks for our findings), but our theoretical starting point is that current tax and transfer considerations are captured by relative income (the difference between an individual's present income and the mean in her country). 
political economy literature. As we will document below, support for redistribution is widespread in Western Europe and extends into income groups whose support for redistribution could not possibly be motivated by short-term tax and transfer maximization alone. We will also show that while support for redistribution by the poor is quite constant, support by the rich is shaped by different macrolevels of inequality. In the section below, we will explain in more detail the reasons why crime is a significant externality of inequality, but we start now by clarifying the relationship between current tax and transfer considerations and concerns for the negative externalities associated with inequality.

As in the Meltzer-Richard model, our argument implies that a rise in inequality that increases the distance between an individual's income and the mean will change her distribution preferences. More importantly, our argument also implies that the current pocketbook consequences of inequality are fully contained in the individual income distance shifts produced by this inequality rise. In other words, the tax and transfer consequences of inequality are picked up by individual income changes.

Macrolevels of inequality, however, can indirectly affect the individual utility function implicit in the previous paragraph. Following Alesina and Giuliano (2011), we can think about this utility function as one in which individuals care not only about their current taxes and transfers but also about some macromeasure of income distribution. ${ }^{3}$ If macro inequality produces economic externalities, we would expect individual preferences to be affected. Of consequence to this article's argument, this model allows for even the rich to be negatively affected by macro inequality and, therefore, for them to support redistribution for purely self-interested reasons.

We are not the first authors to recognize the externalities of inequality as a specific case of a more general model of support for redistribution with macro inequality concerns as well as individual tax and transfer considerations. ${ }^{4}$ Perhaps the clearest example is the literature on externalities of education, which connects average levels of education with aggregate levels of productivity (e.g.) see

\footnotetext{
${ }^{3}$ As suggested by Alesina and Giuliano (2011), different individuals may be affected by different kinds of inequality. For simplicity, in this article we focus on the Gini coefficient, which is the most commonly used measure of inequality in the political economy literature.

${ }^{4}$ The literature in economics and political economy has identified a number of other externalities. If we assume the poor to be less educated, a less effective democracy has been considered a negative externality of inequality by authors like Milton Friedman (1982). There is also some research connecting inequality and environmental degradation (Boyce 1994). In addition, see Beramendi (2012) for an analysis of the externalities of regional inequality.
}

Nelson and Phelps 1966; Perotti 1996; Romer 1990). This framework proposes that, with imperfect credit markets, more inequality means more people below an income level that would allow them to acquire education. The rich, in this case, would support redistribution because of the benefits of a higher education average. But, to our knowledge, we are the first to emphasize crime as the key explanatory factor behind the affluent's support for redistribution.

The paragraphs above suggest that both current tax and transfer and externality considerations matter to redistribution preferences. To integrate the arguments about these two distinct dimensions, however, we will argue that a hierarchy of preferences exists. We propose that poor people value redistribution for its immediate tax and transfer consequences. The redistributive preferences of the rich, on the other hand, are less significantly affected by current tax and transfer considerations. For the rich, the negative externalities of inequality can become more relevant.

We conceive of the solution to the negative externalities of inequality as both time horizon and stakes related. The possibility that the poor have shorter-term motivations than the rich has been explored in the economics and sociology literature before. In economics, the poor have been argued to be more constrained in their investment decisions than the rich (explaining the lower likelihood by the poor to invest in long-term objectives like increasing human capital or saving for retirement). ${ }^{5}$ Complementarily, sociological research has illustrated that lower social class (itself closely related to low income) leads to shorter time horizons (e.g., see O'Rand and Ellis 1974). It is also reasonable to argue that the relative importance of receiving benefits is greater for the poor than the relative importance of paying taxes is for the rich. This difference can be illustrated as follows. From 2001 to 2005, the relative size of benefits (including public pensions) for households in the bottom decile of the distribution represented $71.7 \%$ of household disposable income in Western European countries. ${ }^{6}$ For households in the top decile of the distribution, on the other hand, market income was reduced by just $27.7 \%$ after subtracting taxes. ${ }^{7}$ We expect that, as the stakes of redistribution decline, longer-term considerations related to inequality and crime will increase. We

${ }^{5}$ See, for example, Lawrance (1991) or Dynan, Skinner, and Zeldes (2004).

${ }^{6}$ Even in Greece, where this component is the lowest, it amounted to $44 \%$ of disposable income. Authors' calculations are based on EUROMOD tax simulation data from Paulus et al. (2009, Appendix A, Table 2).

${ }^{7}$ Authors' calculations are based on EUROMOD tax simulation data from Paulus et al. (2009, Appendix A, Table 3). 


\section{FIGURE 1 Macro Inequality and Support for Redistribution}

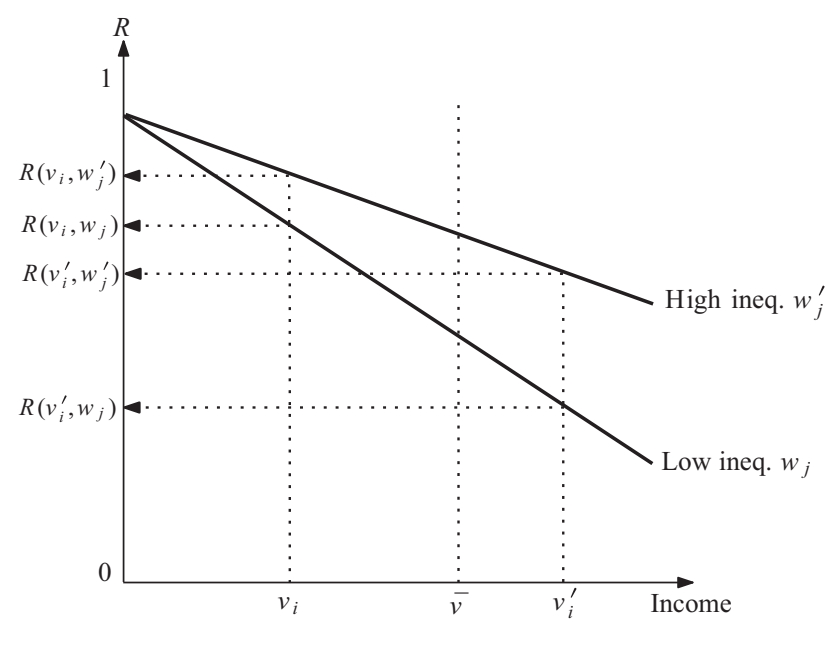

therefore argue in this article that longer time horizons and lower stakes (in relation to current tax and transfer considerations) mean that the negative externalities of inequality will be more important to the rich.

The implications of this article's argument are summarized in Figure 1. We expect the negative externalities of inequality to be associated with less support for redistribution. Since we argue that for the poor externality concerns are trumped by current tax and transfer incentives, redistribution preferences converge regardless of the macrolevel of inequality as income declines. Thus, the redistribution preferences of an individual with low income $v_{i}$ in a low-inequality region $w_{j}$, denoted $R\left(v_{i}, w_{j}\right)$, and in a high-inequality region $R\left(v_{i}, w_{j}^{\prime}\right)$ do not differ by much. In contrast, we expect more macro inequality to promote concerns for its negative externalities for the rich, so that redistribution preferences of a rich individual in a low-inequality region $R\left(v_{i}^{\prime}, w_{j}\right)$ differ starkly from those in a high-inequality region $R\left(v_{i}^{\prime}, w_{j}^{\prime}\right)$.

\section{Macro Inequality and Fear of Crime}

We will show below that the association between macro inequality and redistribution preferences summarized in Figure 1 is supported by the empirical evidence and extraordinarily robust. We argue that the effect of macro inequality is channeled by a number of different factors. The most important of these, as mentioned above, is crime, as a most visible negative externality of inequality.

The canonical model for the political economy of crime and inequality was originally developed by Becker (1968) and first explored empirically by Ehrlich (1973).
The basic argument is simple (see also Bourguignon 2001; Sala-i-Martin 1996). Assume that society is divided into three classes (the poor, the middle, and the rich) with increasing levels of wealth. Assume further that crime pays a benefit, that there is a probability that crime will result in sanction/punishment, and that the proportion of "honest" individuals (people who would not consider crime as an option regardless of its economic benefits) is independent of the level of income (and distributed uniformly across classes). It follows from this straightforward framework that rich people for whom the benefit of crime is small in proportion to their initial wealth will very rarely find crime attractive. It also follows that there will always be a proportion of people among the poor who will engage in crime, and that the benefits from crime are proportional to the wealth of the population. The crime rate implied by this simple model would be positively correlated to the extent of poverty and inequality and negatively correlated to the probability of being caught, the cost of the sanction/punishment, and the proportion of "honest" individuals. ${ }^{8}$

Following this framework, the intuition that crime is related to inequality is easy to understand. With more inequality, the potential gain for the poor from engaging in crime is higher and the opportunity cost is lower. Some early empirical analyses supported this intuition (Ehrlich 1973; Freeman 1982), ${ }^{9}$ but the evidence is not unambiguous. However, while we have described above the relationship between inequality and objective levels of crime, it is fear of crime by the affluent that matters most to our argument. We do understand that, as shown by a well-established sociological literature, fear of crime does not exactly reflect the objective possibility of victimization. As early as 1979 DuBow, McCabe, and Kaplan showed that crime rates reflect victimization of the poor (more than the rich) and that fear levels for particular age-sex groups are inversely related to their victimization (with elderly women having the lowest victimization

\footnotetext{
${ }^{8}$ Note that there is an implicit temporal side to this economic approach to crime; it involves the probability of being caught (in the future) for a crime being committed or not (in the present). Arguably, "the core message of the economic model of criminal behavior is that it can be discouraged by raising its expected 'price" (Lee and McCrary 2005, 1). This, in turn, makes the importance of the price of crime crucially depend on how much potential offenders discount their future welfare. For an explicit temporal model, see, for example, Davis (1988).

${ }^{9}$ More recently, Fajnzylber, Lederman, and Loayza (2002b) used panel data for more than 37 industrialized and nonindustrialized countries from the early 1970s until the mid-1990s to explore the relationship between inequality and violent crime. They found crime rates and inequality to be positively correlated within countries and, particularly, between countries. See also Mehlum, Moene, and Torvik (2005) for cross-country evidence.
} 
rates but the highest fear of crime, and young men having the opposite combination). While we do model explicitly the determinants of fear of crime in the empirical analysis we develop below (and show that macro inequality is a significant one), we are not interested in them per se. ${ }^{10}$ Our argument simply requires rich individuals to believe that there is a connection between macro inequality and crime (following the intuitive logic of the Becker model summarized above). This connection makes sense even if the affluent have concerns for crime that are disproportionately high given their objective probability of victimization. ${ }^{11}$

To anticipate some of our empirical choices below, two additional observations are needed about our argument that macro inequality influences individual concerns about crime as a negative externality. The first one is about the level of macro inequality. Our theoretical argument proposes that the importance of inequality emerges from its relationship to crime as a negative externality. This implies that the relevant level of macro inequality should be one at which a visible connection to crime could be made by individuals. We therefore move away from national data and use regional levels of inequality in the analysis below. Unlike more aggregate levels, regional inequality is both visible and proximate enough to plausibly be related to fear of crime by rich individuals. While it would be good to use even more disaggregated units (e.g., neighborhoods, as in some crime research), the availability of the data at our disposal limits what we can do.

Our argument also implies that rich individuals who are concerned about crime (because they live in unequal areas) are more likely to support redistribution. We

\footnotetext{
${ }^{10}$ We consider fear of crime the equivalent of a subjective assessment of victimization. The higher the fear of crime, the more likely an individual will be to consider himself or herself a potential crime victim. This assessment, we argue, is correlated to macro inequality. The higher the levels of macro inequality, therefore, the more likely the individual considers himself or herself to be a potential crime victim. But this is still a probabilistic assessment that will be less certain or relevant than concerns about current income.

${ }^{11}$ The individuals who are most likely to consider committing crime (i.e., the poor) are generally thought to have very high discount rates (Katz, Levitt, and Shustorovich 2003; Wilson and Herrnstein 1985). Since the likelihood of committing crime is not the focus of our analysis (the determinants of concern for crime are, and particularly the role of inequality), we do not address the price of criminal behavior. But the high discount of future welfare by the poor (who are more likely to consider committing crime in this economic framework) is indeed the basis of our theoretical argument. We adopt the concern for future welfare from this political economy approach to crime but, as suggested above, change the focus to the likelihood that an individual considers himself or herself to be a potential crime victim.
}

assume the affluent's concern for crime to be causally connected to macro inequality, and higher redistribution to be perceived as one of the solutions to the problem. It is clear that other solutions are possible. Most importantly, the affluent may demand protection as a solution to crime (rather than redistribution as a solution to its cause). Recall that objective crime rates in Becker's model are negatively correlated to the probability of being caught and the cost of the sanction/punishment. ${ }^{12}$ While we recognize this as an important issue, we do not consider demands for protection to be incompatible with preferences for redistribution. A number of issues make the comparative costs and benefits of these policies difficult to quantify. They include the implications of these policies in terms of investment in human capital, the encouragement of individual behaviors with positive externalities, the discouragement of behaviors with negative externalities, the spillover from one domain to another (e.g., education and health investments that affect human capital and work effort), the benefits of avoided crime (e.g., early childhood interventions that produce the primary intended impact, better cognitive development, but also later gains in schooling and employment that reduce criminal behavior), and the effects of parental incarceration on children's prospects. ${ }^{13}$ For many rich individuals, uncertainty influences the assessment of the costs and effectiveness of redistribution and security as solutions to crime. ${ }^{14}$ Considering this uncertainty, demands for protection should

\footnotetext{
${ }^{12}$ As argued by Alesina and Giuliano (2011), the implicit assumption in the kind of argument made in this article is that it should cost less for the rich to redistribute than to increase spending on security (i.e., policing, incarceration). This is not an unreasonable assumption. Perhaps the topic of incarceration in the United States, since it is the focus of a large literature, is the best illustration. The cost of incarceration is high. In his widely cited 1996 paper, Freeman calculated that crime control activities cost $2 \%$ of gross domestic product (GDP). Also, incarceration costs often crowd out spending on social policy (for a state comparison within the United States, see Ellwood and Guetzkow 2009). And, while in the short run incarceration reduces unemployment (and the costs of unemployment benefits or active labor market policy), in the long run the costs increase substantially as ex-inmates find themselves in need of public assistance and are often confined to casual or illegitimate employment (e.g., Western, 2006). More explicitly, Donohue and Siegleman (1998) find that diverting resources from incarceration and directing the savings to successful social policy (e.g., preschool interventions) would reduce crime without increasing spending in the United States.

${ }^{13}$ For a review of these assessment issues, see Vining and Weimer (2010).

${ }^{14}$ Moreover, if the poor as potential offenders value their future significantly less than their present welfare, as argued in this article, the effectiveness of deterrence and punishment is put in question (see Lee and McCrary 2005).
} 
not be incompatible with preferences for redistribution. In Western Europe, on which the empirical analysis below focuses, we argue that the rich think of redistribution and protection as complementary policies to mitigate regional crime. $^{15}$

\section{Data}

To explore the theoretical claims explained above, we will first consider the effects of income distance at the individual level and of the macrolevel of inequality. Income distance is meant to capture the effects of individual current tax and transfer considerations and macro inequality those of externality-related factors. The first expectation is that income distance will be a significant determinant of redistribution preferences. We also expect, however, that increasing levels of regional inequality will make the rich more likely to support redistribution. We will then show that the very robust effects of macro inequality are in fact the product of fear of crime among the affluent.

\section{Source and Coverage of Survey Data}

We use data from the European Social Survey (ESS), which includes consistent regional-level identifiers allowing us to match individual and regional information while working with adequate sample sizes. ${ }^{16}$ It also provides a consistent high-quality measure of income. We limit our analyses to four surveys collected between September 2002 and January 2009, which was still a time of relative economic calm. ${ }^{17}$ Our data set covers 129 regions in 14 countries: Austria, Belgium, Germany, Denmark, Spain, Finland, France, Great Britain, Ireland, Netherlands, Norway, Portugal, Sweden, and Switzerland. We treat missing data using multiple imputation (King et al., 2001) to obtain conservative standard errors (more details are given in S.1 in the supporting information).

\section{Redistribution Preferences}

Our dependent variable, preferences for redistribution, is an item commonly used in individual-level research on

\footnotetext{
${ }^{15}$ It is also reasonable to expect the level of privately financed security available in Western Europe to be lower than, for example, that in the United States (where gated communities and private protection are more common). We will return to the American case in the conclusion.

${ }^{16}$ Regional-level identifiers are provided by the NUTS system of territorial classification (Eurostat, 2006). We selected countries that participated in at least two rounds (to obtain usable regional sample sizes) and that provided consistent regional identifiers over time.

${ }^{17}$ We also eliminated surveys after 2007 as a robustness check with no difference in results.
}

\section{TABLE 1 Redistribution Preferences} (Percentages)

\begin{tabular}{lcccc}
\hline $\begin{array}{l}\text { Strongly } \\
\text { Disagree }\end{array}$ & Disagree & Neither & Agree & $\begin{array}{c}\text { Strongly } \\
\text { Agree }\end{array}$ \\
\hline 2.7 & 13.7 & 15.3 & 44.7 & 23.7 \\
\hline
\end{tabular}

Note: Based on five multiply imputed data sets

preferences (e.g., Rehm, 2009). It elicits a respondent's support for the statement "the government should take measures to reduce differences in income levels" measured on a 5-point agree-disagree scale. To ease interpretation, we reverse this scale for the following analyses. Table 1 shows Western Europe to be characterized by a rather high level of popular support for redistribution. While almost $69 \%$ of respondents either agree or strongly agree with the statement that the government should take measures to reduce income differences, only $16 \%$ explicitly express opposition to redistribution. However, despite this apparent consensus, there exists substantial regional variation in redistribution preferences as well as between rich and poor, as we will show below.

\section{The Measure of Relative Income}

Our central measure of material self-interest is the distance between the income of respondents and the mean income in their country (at the time of the survey). In other words, we calculate income distance as a respondent's income minus the country-year income mean. ${ }^{18}$

The ESS captures income by asking respondents to place their total net household income into a number of income bands (12 in 2002-06, 10 in 2008) giving yearly, monthly, or weekly figures. To create a measure of income that closely represents our theoretical concept, income distance, we follow the American politics literature and transform income bands into their midpoints (e.g., Hout, 2004). ${ }^{19}$ We impute the top-coded income category by assuming that the upper tail of the income distribution follows a Pareto distribution (e.g., Kopczuk, Saez, and Song

\footnotetext{
${ }^{18}$ This represents a simple centering, which leaves the distribution of incomes unchanged. However, it takes into account that mean incomes differ over countries. For example, in 2004, the mean income (after purchasing power parities adjustment) in Sweden is 32,721 , whereas in Austria it is 36,122. Note that using untransformed income yields the same pattern of substantive results.

${ }^{19}$ For example, this means that category band J (Less than Eur 1,800 ) becomes midpoint Eur 900 and category R (Eur 1,800 to under Eur 3,600) becomes Eur 2,700. We conducted a robustness test to show that alternative midpoints do not lead to substantively different results (see S.6 in the supporting information).
} 
2010). The purchasing power of a certain amount of income varies across the countries included in our analysis. Simply put, it could be argued that the meaning of being Eur 10,000 below the mean is different in Sweden than in the United Kingdom. ${ }^{20}$ Thus, for each country and each year, we convert a country's currency into PPP-adjusted constant 2005 U.S. dollars. Finally, for each respondent, we calculate the distance between her income and the mean income of her country-year survey. ${ }^{21}$

\section{Crime}

We measure individuals' crime concerns via a survey item that has become "the de facto standard for measuring fear of crime" (Warr 2000, 457). It prompts a respondent to classify whether he or she is afraid of walking alone in the dark with four category responses, ranging from "very safe" to "very unsafe." As we discussed above, this captures subjective crime concerns instead of actual crime. ${ }^{22}$

\footnotetext{
${ }^{20}$ And more importantly, it could be argued that the bulk of rich or poor people would be concentrated in the wealthiest (or most
} unequal) countries, therefore distorting our results.

${ }^{21}$ The distribution of income distances used in our analysis is summarized in Figure S.1 in S.2 in the supporting information. To illustrate the nature of the measure, we aggregate data over all available waves within countries in this figure. The range of income distances reflects interesting national differences (e.g., a more disbursed distribution in Switzerland than in Spain), but the analysis to be developed below will emphasize the general effect of individual income distance on redistribution preferences. Note that we also carry out a number of income robustness tests, including one where we express the distance in percentages of the country-year average income (see Appendix S.6). We also validated the distribution of income in the ESS against a high-quality external reference source, the European Union statistics on income and living conditions (see Appendix S.9).

${ }^{22}$ It could be argued that being afraid of walking alone in the dark is more related to fear of violent crime than to fear of property crime. To the extent that the connection between macro inequality and crime is considered to apply only to property crime, this would be an issue. There are, however, firm grounds to argue that violent crime would have effects similar to property crime in our model. Focusing on actual crime (rather than fear of crime, as we do in our article) in developing countries, Bourguignon argues that the relationship between inequality/poverty and crime in Becker's canonical model is mostly unaffected by the consideration that much of violent crime involves "conflicts that relate to the control of illicit activities like drug dealing, drug trafficking, gambling, and prostitution" rather than "more conventional property crimes like burglary or robbery" $(2001,180)$. This framework adds a new determinant of the general level of crime (namely, the way the illegal sector is organized and the size of the sector), but it "remains true that an increase in urban poverty should, other things being equal, result in an increase in violence" (Bourguignon 2001, 181). Empirically, there is evidence in the criminology and sociology literatures supporting the existence of this link. For analyses of this relationship across countries and over time, see, for example, Fajnzylber, Lederman, and Loayza (2002a), who find that income

\section{Inequality}

A wide number of indices are available to measure inequality, of which the Gini index is the most popular one (e.g., Jenkins, 1991). We perform a subgroup decomposition of the Gini into its regional components (on the subgroup decomposability of inequality, indices, see Cowell 1989; Shorrocks 1980, 1984; Silber 1989). ${ }^{23}$ We calculate our regional Gini measure from our full sample of imputed individual-level data. ${ }^{24}$ Following current "best practice" in economics, we correct for nonrandom sampling and small-sample bias. Sample selection effects are taken into account by using an estimator that weights according to a household's sample inclusion probability (e.g., Cowell, 2000). Since it is well known that Gini estimates are downward biased when calculated from small sample sizes, we employ the small-sample correction proposed by Deltas (2003). Gini values, so constructed, are estimated with error. In fact, every measure of inequality is fraught with error- $a$ fact that is often ignored in current research and that leads to classical errors-in-variables bias. In our analyses, we account for measurement error in our Gini estimates.

First, we use a jackknifing variance estimator to generate regional Gini standard errors (Karagiannis and Kovacevic, 2000). Thus, for each Gini value, we have a point estimate $\hat{w}_{j}$ and a standard error $\sqrt{\operatorname{Var}\left(\hat{w}_{j}\right)}$. Then, in all analyses described below, we account for measurement error following the methodology outlined by Blackwell, Honaker, and King (2015), who propose to treat measurement error in the framework of multiple imputation by creating several "multiply overimputed" data sets, in which the variable measured with error is drawn from a suitably specified distribution representing the variable's

inequality leads to both higher robbery and higher homicide rates, and Fajnzylber, Lederman, and Loayza (2002b), who show the Gini index to be an important factor driving violent crime rates across countries and over time.

${ }^{23}$ Decomposability means that an index can be decomposed into three group-components: $B+W+k$, where $W$ and $B$ represent within- and between-group variance, respectively, whereas $k$ is a residual component. An index is perfectly decomposable if $k=0$. This is true, for example, for members of the family of generalized entropy measures, but it is not necessarily true for the Gini. We decided to use Gini in our main text since it is the most common measure. However, we replicated our results using the Theil index (obtained from a generalized entropy measure with parameter 1), which is perfectly decomposable. The correlation between it and our (small-N corrected) Gini measure is 0.98 .

\footnotetext{
${ }^{24} \mathrm{We}$ use the relative income measure explained above with an imputed top-coded income, which ensures that our measure is not censored (and thus missing top-end inequality).
} 


\section{FIGURE 2 IIllustration of Multiple Overimputation of Gini Measurement Error}

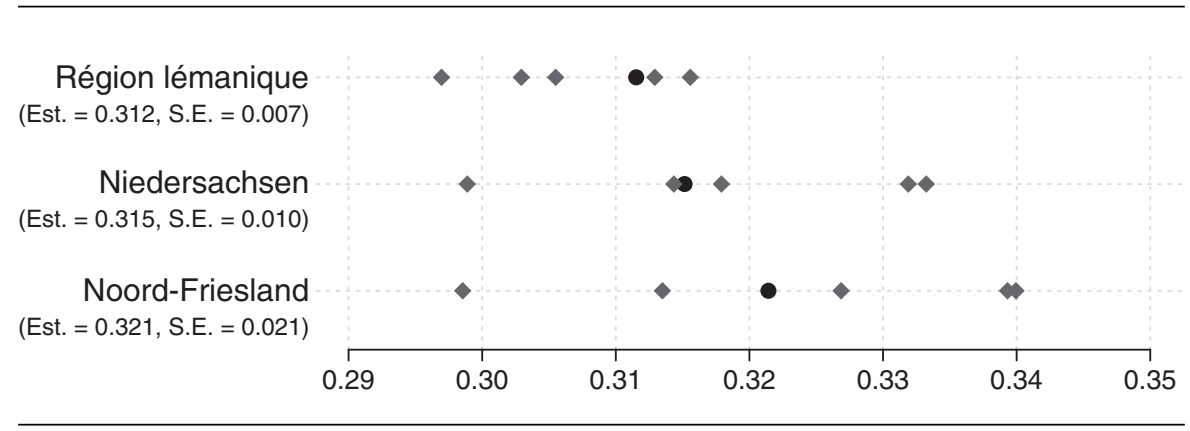

measurement error. ${ }^{25}$ To implement this idea, we generate five overimputed data sets with Gini values for each data set drawn from $w_{j} \sim N\left(\hat{w}_{j}, \operatorname{Var}\left(\hat{w}_{j}\right)\right)$. To illustrate the "penalty" incurred by this measurement error technique, we plot, in Figure 2, three regions with similar Gini estimates but different standard errors. Région lémanique (in Switzerland), Niedersachsen (in Germany), and NoordFriesland (in the Netherlands) share an estimated regional Gini between around 0.31 and 0.32 . For each region, we show the Gini estimate as a black dot and five random multiple-overimputation draws as gray diamonds. Figure 2 clearly shows how larger Gini standard errors lead to a considerable increase in the variance of overimputed values. We use these overimputed values to estimate, all our models five times, average our estimates, and penalize standard errors as a function of the variance between overimputations, as suggested in Blackwell, Honaker, and King (2015) or Rubin (1987). In essence, we account for the errors-in-variables problem caused by the uncertainty of our Gini estimates. ${ }^{26}$

\section{Individual- and Regional-Level Controls}

We control for a range of standard individual characteristics, namely, a respondent's gender, age in years, years of schooling, currently being unemployed, not in the labor force, and the size of the household. We include a measure of social class. While social class is theoretically somewhat ambiguous, it allows us to capture a broad range of socioeconomic outcomes that might be confounded with our income and inequality measures. Furthermore, we

\footnotetext{
${ }^{25}$ In essence, the idea of multiple overimputation is to treat measurement error as a form of partly missing data. Since we already use multiple imputation to deal with missing individual-level data, the multiple overimputation strategy can piggyback on these. For more details, see Blackwell, Honaker, and King (2015).

${ }^{26}$ Note that this is a quite conservative strategy. Our main results are stronger when ignoring measurement error.
}

include a measure of specific skills, differentiating between high and low general skills and specific skills. As controls for existing regional differences, we include the harmonized regional unemployment rate, GDP, the percentage of foreigners (see, e.g., Alesina and Glaeser 2004; Finseraas 2008), and a summary measure of a region's high-tech specialization. ${ }^{27}$ Descriptive statistics for all variables can be found in S.3 in the supporting information.

\section{Methodology Models}

In the first stage of our analysis, we study the link between inequality, relative income, and redistribution preferences $R_{i}^{*}$. Our model specification is

$$
R_{i}^{*}=\alpha\left(v_{i}-\bar{v}\right)+\beta w_{j}+\gamma w_{j}\left(v_{i}-\bar{v}\right)+\boldsymbol{\delta}^{\prime} \boldsymbol{x}_{i j}+\boldsymbol{\epsilon}_{i R} .
$$

This is an ordered probit regression of (latent) redistribution preferences $R_{i}^{*}$ on our covariates of interest and controls. ${ }^{28}$ Here, $\alpha$ captures the effect of relative income, the difference between an individual's income $v_{i}$ and country-year average income $\bar{v}$. The remaining (non-tax and transfer) effect of macro inequality $w_{j}$ is captured by $\beta$. Since we argue that inequality effects are more relevant

\footnotetext{
${ }^{27}$ We used a factor model to generate a summary measure for regional high-tech specialization. We collected Eurostat data on regional information on the share of a region's total workforce employed in science and technology sectors, the share of the economically active population that hold higher degrees, a head count of personnel employed in research and development, and regional total research and development expenditure.

${ }^{28}$ Redistribution preferences $R_{i}^{*}$ are a latent construct obtained
from observed categorical survey responses $R$ (with $K_{r}$ categories)
via a set of thresholds (e.g., Greene and Hensher 2010 ; McK-
elvey and Zavoina 1975) such that $R=r$ if $\tau_{r-1}<R^{*}<\tau_{r}(r=$
$1, \ldots, K_{r}$ ). Thresholds $\tau$ are strictly monotonically ordered, and
the variance of the stochastic disturbances is fixed at $\epsilon_{i R} \sim N(0,1)$,
yielding an ordered probit specification. For a more detailed dis-
cussion of this model setup, see S.4 in the supporting information.
} 
among the rich than among the poor, our model includes an interaction between inequality and individual income with associated effect coefficient $\gamma$. Finally, we include a wide range of individual- and regional-level controls $\boldsymbol{x}_{i j}$, whose effects are represented by $\boldsymbol{\delta}$.

In the second stage of our analysis, we jointly model preferences for redistribution $R_{i}^{*}$ and fear of crime $C_{i}^{*} \cdot{ }^{29}$ A strict test for our argument that fear of crime is an important externality-related determinant of preferences is to estimate its direct effect in our redistribution equation.

$$
\begin{aligned}
C_{i}^{*}=\alpha_{1}\left(v_{i}-\bar{v}\right)+\beta_{1} w_{j}+\boldsymbol{\delta}_{1}^{\prime} \boldsymbol{x}_{1 i j}+\boldsymbol{\epsilon}_{i C} \\
R_{i}^{*}=\lambda_{1} C_{i}+\lambda_{2} C_{i}\left(v_{i}-\bar{v}\right)+\alpha_{2}\left(v_{i}-\bar{v}\right)+\beta_{2} w_{j} \\
+\gamma w_{j}\left(v_{i}-\bar{v}\right)+\boldsymbol{\delta}_{2}^{\prime} \boldsymbol{x}_{2 i j}+\boldsymbol{\epsilon}_{i R} .
\end{aligned}
$$

The direct effect of fear of crime on redistribution preferences is captured by $\lambda_{1}$ and $\lambda_{2}$ in our extended redistribution equation (3). It still includes the main effect of income distance $\alpha_{2}$ as well as the remaining effect of inequality $\beta_{2}$ and its interaction with income distance, captured by $\gamma$. Estimates of individual- and regional-level controls $\boldsymbol{x}_{i j}$ are given by $\boldsymbol{\delta}_{2}$. Our fear of crime equation (2) contains relative income (captured by $\alpha_{1}$ ) and inequality $\left(\beta_{1}\right)$, as well as further controls $\left(\boldsymbol{\delta}_{1}\right)$.

In this second stage, our main interest lies in $\lambda_{1}$ and $\lambda_{2}$, which capture the effect of fear of crime (and its interaction with income) on redistribution preferences net of all other covariate effects. Ideally, if fear of crime plays a significant role in explaining redistribution preferences, we expect to see (a) a significant effect of inequality on fear of crime, $\beta_{1} \neq 0$; (b) a significant effect of fear on preferences, $\lambda_{1} \neq 0$; and (c) a reduction of the (remaining) effect of inequality on the rich, $\gamma$, vis-à-vis Equation (1).

This is a simultaneous (recursive) ordered probit setup, sometimes called an endogenous treatment model (Greene and Hensher 2010, chap. 10).$^{30}$ Errors from the redistribution and crime equations are correlated and thus specified as distributed bivariate normal (Greene 2002, 711-12): [ $\left.\boldsymbol{\epsilon}_{i C}, \boldsymbol{\epsilon}_{i R}\right] \sim B V N(0,0,1,1, \rho)$. Here, $\rho$ captures the correlation of unobservables between both equations that are not due to the direct effect of fear. The model can be seen as a straightforward extension of the

\footnotetext{
${ }^{29}$ Our fear of crime variable $C$ is also ordered categorically and we use the same ordered probit specification as for our redistribution measure, that is, $C=c$ if $\tau_{c-1}<C^{*}<\tau_{c}\left(c=1, \ldots, K_{c}\right)$ with strictly ordered thresholds and errors $\epsilon_{i C} \sim N(0,1)$ for identification.

${ }^{30}$ The system is recursive because $C_{i}$ is allowed to influence $R_{i}$ but not vice versa. The model employs the standard assumption that $E\left(\boldsymbol{\epsilon}_{i C} \mid \boldsymbol{x}_{1 i j}, \boldsymbol{x}_{2 i j}\right)=E\left(\boldsymbol{\epsilon}_{i R} \mid \boldsymbol{x}_{1 i j}, \boldsymbol{x}_{2 i j}\right)=0$.
}

familiar bivariate probit model to ordered data (Butler and Chatterjee, 1997).

The effect of fear of crime is identified from the functional form assumption on the correlation structure between residuals (Heckman 1978; Wilde 2000). ${ }^{31}$ However, to add one more level of robustness to the model (against distributional misspecification), we also use an exclusion restriction in our preference equation (i.e., $\boldsymbol{x}_{1 i j}$ contains at least one covariate not in $\boldsymbol{x}_{2 i j}$ ). We use actual victimization - that is, whether the respondent reports that he, or a member of his household, has been a victim of crime. Having been a victim of crime in the past is a strong determinant of fear of crime. We argue that it can plausibly be excluded from an equation describing preferences; in other words, previous victimization affects preferences for redistribution via raising crime fears, and not via other channels. We have no knowledge of any literature that suggests a link between victimization and redistribution preferences, that is, not channeled via increased fear of crime in the future. ${ }^{32}$

\section{Estimation}

We estimate these two equations jointly by maximum likelihood (Butler and Chatterjee, 1997). ${ }^{33}$ In this setup, individuals within the same region and country will share unobserved characteristics, rendering the standard assumption of independent errors implausible (e.g., Moulton 1990; Pepper 2002). Thus, to account for arbitrary within-region and within-country error correlations, we estimate standard errors using nonparametric bootstrapping, resampling regions and countries, in order to yield conservative standard errors (e.g., Wooldridge 2003). ${ }^{34}$

\footnotetext{
${ }^{31}$ More technically, a full rank condition of the covariate matrix is enough, as discussed earlier by Heckman (1978). This is achieved by the existence of at least one continuous, varying, exogenous regressor in each equation, "an assumption which is rather weak in economic applications” (Wilde 2000, 312).

${ }^{32}$ Nonetheless, one should keep in mind that even if this exclusion restriction should be violated, the model is still identified via the bivariate normal distribution.

${ }^{33}$ See Yatchew and Griliches (1985) for a discussion of the disadvantages of two-step estimation. Freedman and Sekhon (2010) caution against convergence to local maxima, which we check by (a) running our model several times from dispersed initial values and (b) bootstrapping individual observations. In each case, we get essentially the same results.

${ }^{34}$ Alternatively, one might employ heteroskedasticity-consistent
standard errors, which are asymptotically equivalent to boot-
strapped standard errors, or multilevel models. However, to
correctly capture the correlation structure between units, their
"clustering" should be specified at the highest level. In our case, this
implies robust standard errors or random effects based on only 14
} 
FIgURE 3 Support for Redistribution among Rich and Poor (A), Inequality (B), and Fear of Crime (C), by Region
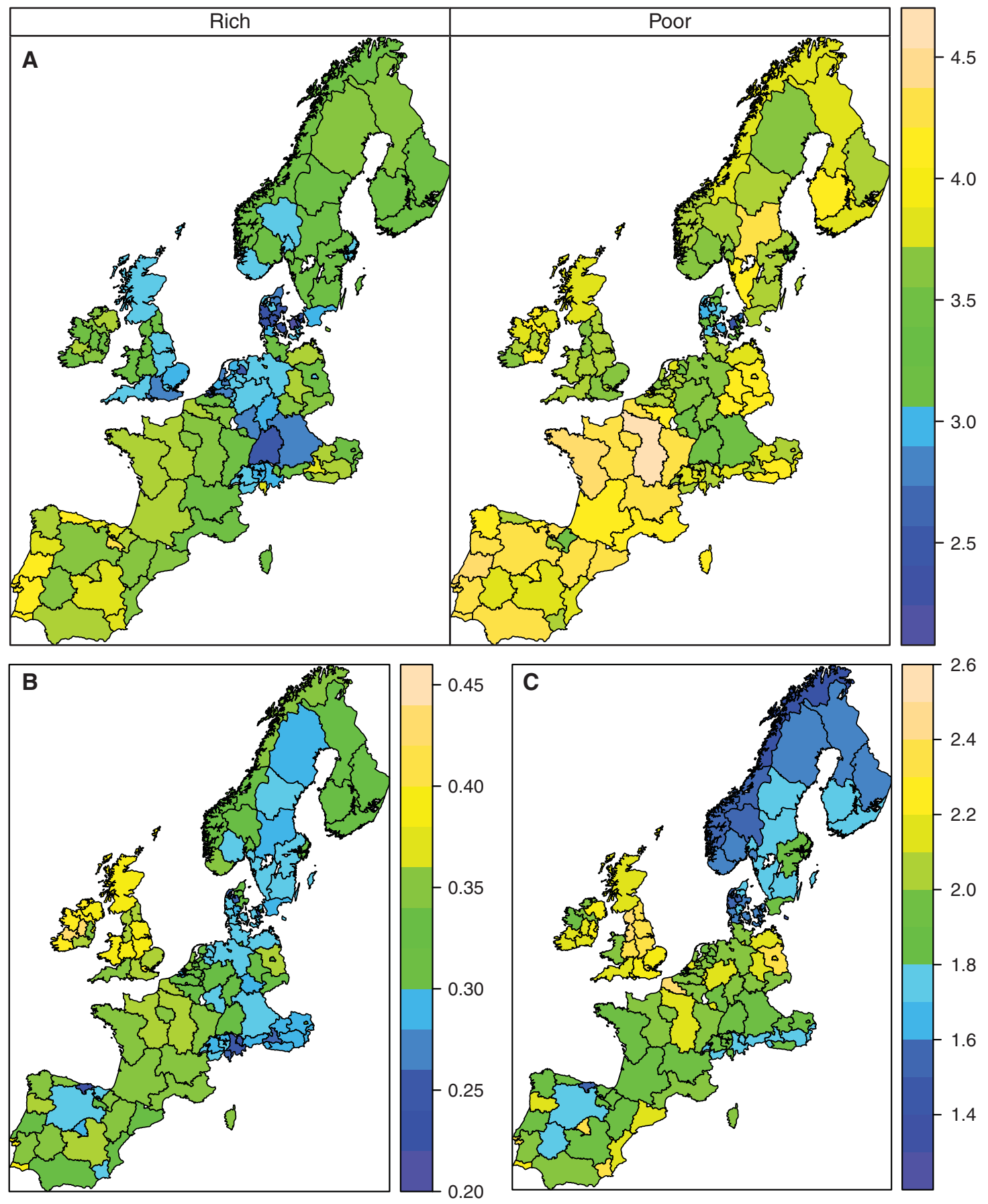

(country) units. Both methods can be severely biased with a small number of clusters (see, e.g., Angrist and Pischke 2008; Stegmueller 2013a). Thus, we opt for the nonparametric bootstrap, which is not adversely affected by sample size. Note that the decision to employ bootstrapping simply leads to conservative standard errors but does not in any way drive our results.

\section{Regional Variation in Inequality and Preferences}

We have argued above that rich individuals who are concerned about crime because they live in unequal areas will be more likely to support redistribution. Panel (A) 
of Figure 3 represents a first illustration of the two things this article's argument is about: the existence of regional variation in support for redistribution among the rich and among the poor. It captures the average level of support (i.e., the mean of the 5-point scale) for redistribution in each of the regions in the sample: first among the rich (those with household incomes 30,000 PPP-adjusted 2005 U.S. dollars above the mean, the 90th percentile in the sample's income distribution) and then among the poor (with household incomes 25,000 PPP-adjusted 2005 U.S. dollars below the country-year mean, the 10th percentile).

Figure 3(A), strongly suggests the existence of a general relative income effect. By looking at the two panels side by side, we can see that support for redistribution of the poor is almost always higher than that of the rich (there are some exceptions, but these are limited to very few regions where support for redistribution is generally very high for both groups). While the average regional support for redistribution for the poor is close to 4 in the 5-point scale (the "Agree" choice), the average for the rich is closer to 3 (the "Neither Agree nor Disagree" choice). The figure also shows a remarkable amount of regional variation. The lowest support for redistribution among the rich (2.2 on the 5-point scale, close to the "Disagree" choice) can be found in a Danish region (Vestsjællands Amt), whereas the highest support among the rich (4.6) is in a Spanish one (La Rioja). For the poor, the highest support for redistribution (4.5) is in France (ChampagneArdenne, Picardie, and Bourgogne), whereas the lowest support (2.6) is again to be found in Vestsjællands Amt.

More importantly for the arguments in this article, the degree of regional variation within countries in Figure 3(A) is remarkable. Looking at the redistribution preferences of the rich, this variation can be illustrated by comparing two regions in the United Kingdom. In the South East of England, the rich exhibit low support for redistribution (2.8), whereas in Northern Ireland they are much more supportive (3.8, a whole point higher). The preferences of the poor can also be used as an illustration. In Denmark, the poor in Storstrøms Amt are much more supportive of redistribution (3.7) than in Vestsjællands Amt (2.6).

The more systematic analysis to be developed below will help explain the redistribution patterns shown in Panel (A) of Figure 3, but an initial illustration of our main explanatory variables is offered in Panels (B) and (C). Panel (B) captures regional inequality (the Gini index calculated from the individual-level surveys, as explained in the previous section) and Panel (C) fear of crime (measured as the regional average of the four-category re- sponses to the survey question about respondents being afraid of walking alone in the dark). The figures show a general correlation between inequality and fear of crime and again a remarkable amount of regional variation. The lowest levels of inequality and fear of crime can be found in regions of Denmark and Switzerland (and also in Cantabria, Spain). The highest levels of both variables are in some regions in the United Kingdom (e.g., London, the North West, or the East Midlands), in Ireland's Mid-East, and in Portugal (Lisbon).

It is also the case that there is a significant degree of regional variation within countries. Looking at inequality in Panel (B), there are stark differences between the South of England and Scotland or between Andalucia and Cantabria in Spain. Looking at fear of crime in Panel (C), the regional differences in Spain are again significant (but so are they in Sweden).

\section{Model Results}

In order to save space, we do not present tables with coefficient estimates (full tables are available in S.5 in the supporting information). Instead, we focus on quantities of interest and calculate both predicted probabilities and marginal effects for the rich and poor conditional on different levels of macro inequality. Suffice it to say at this stage that parameter estimates for income, inequality, and their interaction are statistically significant. As expected, we find that income distance has a negative effect on redistribution preferences: The further above someone is from the mean income, the more she opposes income redistribution. We also find that increasing macro inequality goes hand in hand with higher preferences for redistribution, and that this relationship increases with an individual's income distance.

To gain a more intuitive understanding of the role of inequality, we calculate average predicted probabilities for supporting redistribution among rich and poor individuals living in high- or low-inequality regions, respectively. ${ }^{35}$ In Figure 4, the only factors that change in the comparison of predicted probabilities, therefore, are income distance to the mean (on the $\mathrm{x}$-axis) and the two

\footnotetext{
${ }^{35}$ In this section, we define support for redistribution as a response of "strongly agree" on our redistribution measure. Average predicted probabilities are calculated by setting the variables in question to the chosen values while holding all other variables at all their observed values. The final estimates are the average of these predictions. We do the same below when calculating average marginal effects. See Hanmer and Kalkan (2013) for a recent discussion of the advantages of this strategy (vis-à -vis simple predicted probabilities calculated at sample averages).
} 


\section{FIgURE 4 Probability of Support for Redistribution by Income and Inequality (with 90\% Confidence Intervals).}

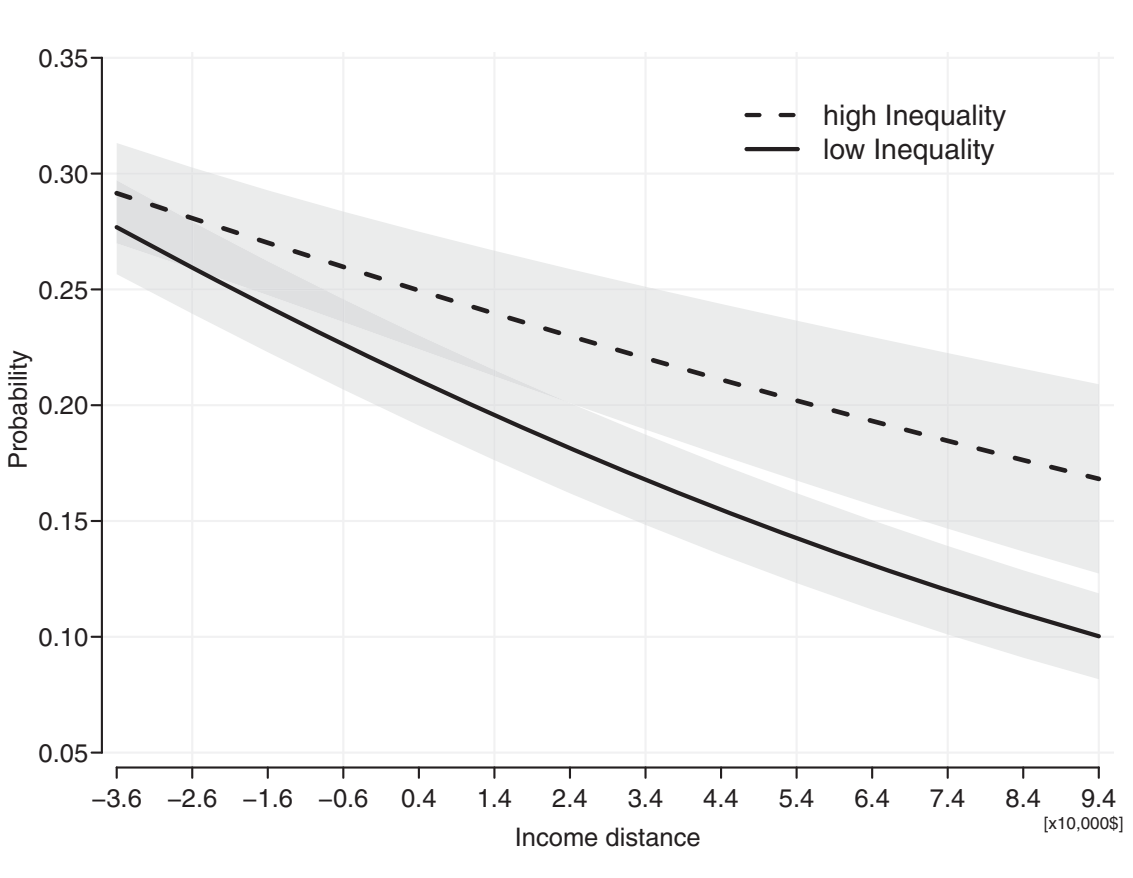

levels of macro inequality (in the solid and dashed lines). High inequality refers to Gini values at the 90th percentile of the regional distribution (as in the East Midlands in the United Kingdom), whereas low inequality refers to the 10th (as in Oberösterreich in Austria). The results provide a clear picture of the correspondence between our theoretical argument (in Figure 1) and the empirical findings.

Since, statistically, it is not strictly correct to infer the significance of the difference from our (non-)overlapping confidence intervals (see Afshartous and Preston 2010 for a detailed argument), we look at the differences between the poor and the rich more systematically in Table 2. As before, we define rich and poor as the 90th and 10th percentiles of the income distribution. ${ }^{36}$ The results in Panel (A) provide strong confirmation of our theoretical expectations. Among the poor, the probability of strongly supporting redistribution remains at similar levels regardless of the level of inequality, changing only from 26 to $28 \%$ when moving from low to high inequality. In contrast, the effect of macro inequality is more pronounced among the rich: Explicit support for redistribution rises from 17\% in low-inequality regions to over $22 \%$ in high-inequality areas. In other words, the difference in predicted support for redistribution due to increased inequality is more than

\footnotetext{
${ }^{36}$ Using the 90th percentile defines "the rich" as being 30,000 (constant, PPP-adjusted) euros above the national mean. Note that the same substantive pattern of results is obtained when we define "the rich" as those only 20,000 euros above the mean.
}

twice as large among the rich (and it is a statistically significant difference).

To put this conclusion to a stricter test, we calculate the average marginal effects of macro inequality for rich and poor individuals, shown in Panel (B) of Table 2 together with their respective standard errors and 95\% confidence bounds. The results further support our argument. The marginal effect of inequality among rich individuals is large and statistically different from zero. In contrast, we find a considerably smaller marginal effect among the poor, with a $95 \%$ confidence interval that includes zero. Higher levels of macro inequality increase the probability of support for redistribution among the rich, but they make little difference to the poor.

It is important to point out that the estimates in Table 2 represent a significant amount of support for the relationship hypothesized in Figure 1. As we expected, redistribution preferences converge for the poor regardless of the macrolevel of inequality. We also find the redistribution preferences of the rich to diverge as macro inequality grows. While we need to keep in mind that our results emphasize the effects of regional (and not national) inequality, some influential alternative hypotheses are contradicted by our evidence.

A prominent literature posits that, in high-inequality contexts, the poor are diverted from the pursuit of their material self-interest. This effect would imply that, in 
TABLE 2 Support for Redistribution

\begin{tabular}{|c|c|c|c|c|c|c|c|}
\hline \multicolumn{4}{|c|}{ (a)Predicted Probabilities } & & \multicolumn{3}{|c|}{ (b) Marginal Effect of Inequality } \\
\hline & & \multicolumn{2}{|c|}{ Gini } & & \multicolumn{3}{|c|}{ Marginal Effect of Gini } \\
\hline & & Low & High & & Est. & S.E. & $95 \% \mathrm{CI}$ \\
\hline \multirow[t]{2}{*}{ Income } & Poor & 25.8 & 28.0 & Poor & 0.246 & 0.202 & {$[-0.150,0.643]$} \\
\hline & Rich & 17.4 & 22.5 & Rich & 0.568 & 0.253 & {$[0.069,1.067]$} \\
\hline
\end{tabular}

Note: Panel (a) shows predicted probabilities by income and inequality; Panel (b) shows marginal effect of inequality among rich and poor. Calculated from Equation (1). All estimates are available in Table S.3, Appendix S.5. Region-county bootstrapped, multiple overimputation standard errors.

contradiction to Figure 1, redistribution preferences would diverge for the poor and converge for the affluent. Perhaps the most well-known example of these arguments is its application to the high-inequality example of the United States and the contention that second-dimension issues (particularly cultural and social) outweigh economic ones for the American working class. ${ }^{37}$ More comparatively, Shayo's (2009) important contribution to the political economy of identity formation follows a similar logic. ${ }^{38}$ If these arguments were correct, we would expect the poor in unequal countries to be distracted from their material self-interested redistribution preferences, to the extent that these second-dimension concerns are correlated with macrolevel inequality. ${ }^{39}$ The results presented above suggest that the poor are not distracted from the pursuit of their present material self-interest in regions with higher levels of macro inequality, whether because of second-dimension concerns or prospects of upward mobility.

In another theoretical alternative, Lupu and Pontusson (2011) propose that macrolevels of equality are related to empathy. They argue that, because of social affinity,

\footnotetext{
${ }^{37}$ See Frank (2004), the critique in Bartels (2006), and the comparative analyses by De La O and Rodden (2008), Huber and Stanig (2011), and Stegmueller (2013b).

${ }^{38}$ Shayo's (2009) theoretical model emphasizes two identity dimensions: economic class and nationality. As a result of status differences, the poor are more likely than the rich to identify with the nation rather than their class in high-inequality countries. Because they take group interests into account, moreover, the poor who identify with the nation are less supportive of redistribution than the poor who identify with their class.

${ }^{39}$ A similar expectation emerges from the "prospect of upward mobility" (POUM) hypothesis. Benabou and Ok (2001) argue that the poor do not support high levels of redistribution because of the hope that they, or their offspring, may make it up the income ladder. To the extent that mobility is correlated with macrolevel inequality (something often argued in relation to the United States but that is empirically not clear), we would expect a different relationship between income and preferences from that depicted in Figure 1.
}

individuals will be inclined to have more similar redistribution preferences to those who are closer to them in terms of income distance. While Lupu and Pontusson emphasize skew (rather than Gini) and the position of the middle class, their argument implies that social affinity would make the rich have higher levels of support for redistribution as inequality decreases and their social distance from the middle class and the poor is reduced (the opposite of the predictions in Figure 1). A similar relationship would be expected by the approach that relates beliefs in a just world to redistribution preferences. To the extent that macrolevels of inequality are related to these beliefs (e.g., that inequality rewards the hardworking and punishes the lazy), we would observe lower levels of support for redistribution from the rich in countries with higher inequality and a higher normative tolerance for it (Alesina and Glaeser 2004; Benabou and Tirole 2006). Our evidence fails to support these arguments.

As we mentioned above, an influential literature in comparative political economy has argued that if macro inequality means that the rich are more likely to become poor, current generosity may not reflect externality concerns but the demand for insurance against an uncertain future (Iversen and Soskice 2009; Moene and Wallerstein 2001; Rehm 2009). To address this, we introduced an explicit measure of risk into the analysis. An important component of the demand for insurance and redistribution has to do with the risk of becoming unemployed. We operationalize risk as specific skills. Iversen and Soskice (2001) argue that individuals who have made risky investments in specific skills will demand insurance against the possible future loss of income from those investments. Our measure of skills (taken from Fleckenstein, Saunders, and Seeleib-Kaiser 2011) distinguishes among specific high and low general skills, and it is meant to capture this individual risk directly. The effects of risk are not an issue of primary importance to our analysis; we are only interested in showing that our findings are robust to the 
inclusion of these explicit measures of risk. This is indeed the case in Figure 4 and Table 2. ${ }^{40}$

In the previous sections, we went on to argue that the main mechanism linking inequality and redistribution preferences is fear of crime. In the second stage of our analysis, we thus estimate our simultaneous ordered probit model linking inequality to fear of crime, which then is expected to shape preferences for redistribution (all estimates for both equations are available in Table S.4, in $S .5$ in the supporting information). In our fear of crime equation, we include a number of factors identified in the literature (e.g., Hale, 1996). We find, not surprisingly, that having previously been a victim of crime increases a person's fear of crime and that other variables affect fear of crime in the expected directions. More importantly, our results show that, in agreement with our argument, in regions with higher levels of inequality, respondentswhether rich or poor-are more afraid of crime. We also find clear evidence that fear of crime matters for redistribution preferences. Individuals who are more afraid of crime show higher levels of support for redistribution, a relationship that is slightly stronger among those with higher incomes. A test for independence of fear of crime and redistribution equations is rejected $(\mathrm{F}=14.8$ at 2df.). We also find that the direct effect of macro inequality becomes statistically insignificant once we explicitly estimate the effect of fear of crime.

Again, a stricter test of our hypotheses can be obtained by calculating average marginal effects. We expect to find (a) a significant (both in the statistical and substantive sense) marginal effect of fear of crime on redistribution preferences and (b) the size of the remaining effect of macro inequality (operating through other channels) to be reduced. Table 3 shows average marginal effects of fear of crime and inequality among the rich. As already indicated by our coefficient estimates, the marginal effect of fear of crime is strong and clearly different from zero. More importantly, we find the remaining marginal effect of inequality to be greatly limited. In fact, it is reduced to such an extent that its confidence interval includes zero. This result does not, of course, negate the existence of other relevant channels linking inequality and preferences, but it at least signifies that externalities go a long way in explaining the effect of inequality on redistribution preferences.

\footnotetext{
${ }^{40}$ For the estimates of the skills variables, see Appendix S.5 in the supporting information. Furthermore, using Iversen and Soskice's (2001) alternative measure of skill specificity leads to the same results, as shown in Appendix S.6. in the supporting information.
}

\section{TABLE 3 Effects of Fear of Crime and Inequality among the Rich}

\begin{tabular}{lccc}
\hline & \multicolumn{3}{c}{ Marginal Effect among Rich } \\
\cline { 2 - 4 } & Est. & S.E. & 95\% CI \\
\hline Fear of crime & 0.099 & 0.033 & {$[0.035,0.163]$} \\
Gini & 0.317 & 0.261 & {$[-0.198,0.833]$} \\
\hline
\end{tabular}

Note: Table indicates average marginal effects for predicted strong support of redistribution. Calculated from Equations (2) and (3). All estimates are available in Table S.4, Appendix S.5. Regioncounty bootstrapped, multiple overimputation standard errors.

\section{Robustness Tests}

We conducted a large number of robustness tests studying alternative model specifications (too many to include here). They are described in detail in S.6 in the supporting information. To capture alternative macro explanations, we included existing levels of redistribution, regional transfers, measures of urbanization, and population density. To capture alternative individual-level explanations, we included religion, ideology, an alternative measure of skill specificity, and a measure of altruism. We also carried out a number of tests for our measurements of income and inequality. Our estimates (in Table S.5, Appendix S.6) show that our core conclusions remain valid under these alternatives. Furthermore, Appendix S.7 includes specifications using country and year fixed effects, again confirming our main results.

\section{Conclusion}

It is appropriate to conclude this article by reemphasizing the importance of our main results and exploring some of their implications for further research. The evidence demonstrates that for the poor, externality concerns are trumped by immediate disposable income incentives and that redistribution preferences converge regardless of the macrolevel of inequality as income declines. By contrast, macro inequality promotes concerns about negative externalities for the rich. We showed that the redistribution preferences of a rich individual in a low-inequality region differ starkly from those of a similarly rich individual in a high-inequality region and, more importantly, that this difference is motivated by fear of crime.

In some ways, this is a profoundly unintuitive result (the rich are more supportive of redistribution in 
those regions where inequality is highest). We do provide an intuitive solution for this puzzle (the concern for crime by the rich), but it is germane to ask whether our results emerge from the idiosyncrasies of our particular sample. We have mentioned before that the rich, if concerned about the externalities of inequality, could do (at least) two things: reduce inequality through redistribution, or reduce its potential consequences by demanding more protection. We have argued that demands for redistribution and security can be complementary, but it is tempting to think that the rich in Western Europe may be more likely than the rich in other regions to think of redistribution as an attractive option. In related (but preliminary) work reproducing the analysis presented in this article, however, the effect of macro inequality in the United States is remarkably similar to what we find in Western Europe. The American data allow us to directly address the possibility of a security versus redistribution trade-off. Looking at inequality at the state level in the United States, the evidence we find supports the idea that these preferences are complementary, as individuals more likely to support redistribution are also more likely to support increasing the resources dedicated to public security provision. While this is a topic we hope to do further research on, we will mention that our findings connect with a significant literature of the consequences of inequality in the United States. Using American data and focusing on voting behavior, Gelman et al. (2008) find, like us, that the poor (whether in Connecticut or Mississippi) are quite similar. It seems to be the case that it is the rich who are responsible for some of the political differences we see (in Western Europe as well as the United States). And this is perhaps the most important take-home message in our article.

Our research, moreover, runs counter to a set of findings in the psychology literature about the influence of income on charitable giving and prosocial behavior. Using surveys conducted in the United States, some authors find that lower-income individuals give proportionally more to charitable causes than higher-income ones (e.g., see James and Sharpe 2007). ${ }^{41}$ Other authors using experimental data find that subjective perceptions of one's social class promote generosity and charitable donations (see Piff et al. 2010). This article does not address the role of altruism in determining voluntary donations. But our results do indicate that, irrespective of charity and controlling for altruism, ${ }^{42}$ the rich in Western Europe are more likely to support government-based redistribution

\footnotetext{
${ }^{41}$ This research has found wide resonance in the popular press. See Greve (2009) or Johnston (2005).

${ }^{42}$ See the altruism analysis in Appendix S.6.
}

when regional inequality makes them more concerned about crime.

Going back to the unintuitive nature of our findings, one might finally ask why we do find less redistributive systems in precisely the places where the rich are more supportive of redistribution. We think this is an important question in need of a significant amount of further research. As McCarty and Pontusson (2009) note, models of the political economy of redistribution involve two separate propositions: There is a "demand" side, concerning the redistribution preferences of voters, and a "supply" side, concerning the aggregation of these preferences and the provision of policy. In this article, we have focused on the first proposition and ignored the second. We hope that the arguments in this article clarify the role of preferences as an essential first step for an accurate understanding of the supply of redistribution.

\section{References}

Afshartous, David, and Richard A. Preston. 2010. "Confidence Intervals for Dependent Data: Equating Non-overlap with Statistical Significance." Computational Statistics and Data Analysis 54: 2296-2305.

Alesina, Alberto, and Paola Giuliano. 2011. "Preferences for Redistribution." In Handbook of Social Economics ed. Jess Benhabib, Alberto Bisin, and Matthew O. Jackson. San Diego, CA: North-Holland, 93-131.

Alesina, Alberto, and Edward L. Glaeser. 2004. Fighting Poverty in the US and Europe: A World of Difference. Oxford: Oxford University Press.

Angrist, Joshua D., and Jorn-Steffen Pischke. 2008. Mostly Harmless Econometrics: An Empiricist's Companion. Princeton, NJ: Princeton University Press.

Bartels, Larry M. 2006. "What's the Matter with What's the Matter with Kansas?" Quarterly Journal of Political Science 1 (1): 201-26.

Bean, Clive, and Elim Papadakis. 1998. "A Comparison of Mass Attitudes towards the Welfare State in Different Institutional Regimes, 1985-1990.” International Journal of Public Opinion Research 10(3): 211-36.

Becker, Gary S. 1968. "Crime and Punishment: An Economic Approach.” Journal of Political Economy 76(2): 169-217.

Benabou, Roland, and E. A. Ok. 2001. "Social Mobility and the Demand for Redistribution: The Poum Hypothesis." Quarterly Journal of Economics 116(2): 447-87.

Benabou, Roland, and Jean Tirole. 2006. "Belief in a Just World and Redistributive Politics." Quarterly Journal of Economics 121(2): 699-746.

Beramendi, Pablo. 2012. The Political Geography of Inequality: Regions and Redistribution. Cambridge: Cambridge University Press.

Blackwell, Matthew, James Honaker, and Gary King. 2015. "Multiple Overimputation: A Unified Approach to 
Measurement Error and Missing Data." Sociological Methods and Research Preprint. DOI: 10.1177/0049124115585360.

Bourguignon, Francois. 2001. "Crime As a Social Cost of Poverty and Inequality: A Review Focusing on Developing Countries." In Facets of Globalization International and Local Dimensions of Development, ed. S. Yusuf, S. Evenett, and W. Wu. Washington DC: World Bank, 171-191.

Boyce, James K. 1994. "Inequality as a Cause of Environmental Degradation.” Ecological Economics 11(3): 169-78.

Butler, John S., and Patrali Chatterjee. 1997. "Tests of the Specification of Univariate and Bivariate Ordered Probit." Review of Economics and Statistics 79(2): 343-47.

Cowell, Frank A. 1989. "Sampling Variance and Decomposable Inequality Measures.” Journal of Econometrics 42(1): 27-41.

Cowell, Frank A. 2000. "Measurement of Inequality.” In Handbook of Income Distribution, Vol. 1, ed. Anthony B. Atkinson and Francois Bourguignon. Amsterdam: Elsevier, 87-166.

Davis, Michael L. 1988. "Time and Punishment: An Intertemporal Model of Crime." Journal of Political Economy 96(2): 383-90.

De La O, Ana L., and Jonathan A. Rodden. 2008. "Does Religion Distract the Poor? Income and Issue Voting around the World.” Comparative Political Studies 41(4-5): 437-76.

Deltas, George. 2003. "The Small-Sample Bias of the Gini Coefficient: Results and Implications for Empirical Research.” Review of Economics and Statistics 85(1): 226-34.

Donohue, John, and Peter Siegleman. 1998. "Allocating Resources among Prisons and Social Programs in the Battle against Crime." Journal of Legal Studies 27(1): 1-43.

DuBow, Fred, Edward McCabe, and Gail Kaplan. 1979. "Reactions to Crime: A Critical Review of the Literature." Technical report, Department of Justice, Office of Justice Programs, Washington, DC.

Dynan, Karen E., Jonathan Skinner, and Stephen P. Zeldes. 2004. "Do the Rich Save More?" Journal of Political Economy 112(2): 397-444.

Ehrlich, Isaac. 1973. "Participation in Illegitimate Activities: A Theoretical and Empirical Investigation." Journal of Political Economy 81(3): 521-65.

Ellwood, John W., and Joshua Guetzkow. 2009. "Footing the Bill: Causes and Budgetary Consequences of State Spending on Corrections." In Do Prisons Make Us Safer? The Benefits and Costs of the Prison Boom, ed. Michael A. Stoll and Steven Raphael. New York: Russell Sage Foundation, 207-238.

Eurostat. 2007. Regions in the European Union: Nomenclature of Territorial Units for Statistics. NUTS 2006. Luxembourg: Office for Official Publications of the European Communities.

Fajnzylber, Pablo, Daniel Lederman, and Norman Loayza. 2002a. "Inequality and Violent Crime." Journal of Law and Economics 45(1): 1-40.

Fajnzylber, Pablo, Daniel Lederman, and Norman Loayza. 2002b. "What Causes Violent Crime?" European Economic Review 46(7): 1323-57.

Fehr, Ernst, and Klaus M. Schmidt. 2006. "The Economics of Fairness, Reciprocity, and Altruism: Experimental Evidence and New Theories." In Handbook of the Economics of Giving, Reciprocity, and Altruism, ed. Serge-Christophe Kolm and Jean Mercier Ythier. Amsterdam: Elsevier, 615-691.
Finseraas, Henning. 2008. "Immigration and Preferences for Redistribution: An Empirical Analysis of European Survey Data." Comparative European Politics 6(4): 407-31.

Finseraas, Henning. 2009. "Income Inequality and Demand for Redistribution: A Multilevel Analysis of European Public Opinion." Scandinavian Political Studies 32(1): 94-119.

Fleckenstein, Timo, Adam M. Saunders, and Martin SeeleibKaiser. 2011. "The Dual Transformation of Social Protection and Human Capital: Comparing Britain and Germany." Comparative Political Studies 44(12): 1622-50.

Frank, Thomas. 2004. What's the Matter with Kansas? How Conservatives Won the Heart of America. New York: Metropolitan Books.

Freedman, David A., and Jasjeet S. Sekhon. 2010. "Endogeneity in Probit Response Models." Political Analysis 18(2): 138-50.

Freeman, Richard B. 1982. "Crime and the Labor Market." National Bureau of Economic Research working paper 1031.

Freeman, Richard B. 1996. "Why Do So Many Young American Men Commit Crimes and What Might We Do About It?". Journal of Economic Perspectives 10(1): 25-42.

Friedman, Milton. 1982. Capitalism and Freedom. Chicago: University of Chicago Press.

Gelman, Andrew, David K. Park, Boris Shor, Joseph Bafumi, and Jeronimo Cortina. 2008. Red State, Blue State, Rich State, Poor State: Why Americans Vote the Way They Do. Princeton, NJ: Princeton University Press.

Gilens, Martin. 2005. "Inequality and Democratic Responsiveness.” Public Opinion Quarterly 69(5): 778-96.

Gouveia, Miguel, and Neal A. Masia. 1998. "Does the Median Voter Model Explain the Size of Government? Evidence from the States." Public Choice 97(1-2): 159-77.

Greene, William, and David Hensher. 2010. Modeling Ordered Choices: A Primer. Cambridge: Cambridge University Press.

Greene, William H. 2002. Econometric Analysis. Upper Saddle River, NJ: Prentice Hall.

Greve, Frank. 2009. “America's Poor Are Its Most Generous." Seattle Times, http://seattletimes.nwsource.com.

Haider, Steven, and Gary Solon. 2006. "Life-Cycle Variation in the Association between Current and Lifetime Earnings." American Economic Review 96(4): 1308-20.

Hale, Chris. 1996. "Fear of Crime: A Review of the Literature." International Review of Victimology 4(2): 79-150.

Hanmer, Michael J., and Kerem Ozan Kalkan. 2013. "Behind the Curve: Clarifying the Best Approach to Calculating Predicted Probabilities and Marginal Effects from Limited Dependent Variable Models." American Journal of Political Science 57(1): 263-77.

Heckman, James J. 1978. "Dummy Endogenous Variables in a Simultaneous Equation System.” Econometrica 46(6): 93159.

Hout, Michael. 2004. "Getting the Most out of the GSS Income Measures.” GSS Methodological Report 101.

Huber, John D., and Piero Stanig. 2011. "Church-State Separation and Redistribution." Journal of Public Economics 95(78): 828-36.

Iversen, Torben, and David Soskice. 2001. "An Asset Theory of Social Policy Preferences." American Political Science Review 95(4): 875-93. 
Iversen, Torben, and David Soskice. 2009. "Distribution and Redistribution: The Shadow of the Nineteenth Century." World Politics 61(3): 438-86.

James, Russell N., and Deanna L. Sharpe. 2007. "The Nature and Causes of the U-Shaped Charitable Giving Profile." Nonprofit and Voluntary Sector Quarterly 36(2): 218-38.

Jenkins, Stephen. 1991. "The Measurement of Income Inequality." In Economic Inequality and Poverty: International Perspectives, ed. Lars Osberg. Armonk, NY: M.E. Sharpe, 3-38.

Johnston, David Cay. 2005. "Study Shows the Superrich Are Not the Most Generous."New York Times.

Karagiannis, Elias, and Milorad Kovacevic. 2000. “A Method to Calculate the Jackknife Variance Estimator for the Gini Coefficient." Oxford Bulletin of Economics and Statistics 62(1): $119-22$.

Katz, Lawrence, Levitt, Steven D. Levitt, and Ellen Shustorovich. 2003. "Prison Conditions, Capital Punishment, and Deterrence." American Law and Economics Review 5(2): 318-43.

Kenworthy, Lane, and Jonas Pontusson. 2005. "Rising Inequality and the Politics of Redistribution in Affluent Countries." Perspectives on Politics 3(3): 449-71.

King, Gary, James Honaker, Anne Joseph, and Kenneth Scheve. 2001. "Analyzing Incomplete Political Science Data: An Alternative Algorithm for Multiple Imputation." American Political Science Review 95(1): 49-69.

Kopczuk, Wojciech, Emmanuel Saez, and Jae Song. 2010. “Earnings Inequality and Mobility in the United States: Evidence from Social Security Data since 1937." Quarterly Journal of Economics 125(1): 91-128.

Lawrance, Emily C. 1991. "Poverty and the Rate of Time Preference: Evidence from Panel Data." Journal of Political Economy 72(2): 54-77.

Lee, David S., and Justin McCrary. 2005. "Crime, Punishment, and Myopia." National Bureau of Economic Research working paper 11491.

Lindert, Peter H. 1996. "What Limits Social Spending?” Explorations in Economic History 33: 1-34.

Lupu, Noam, and Jonas Pontusson. 2011. "The Structure of Inequality and the Politics of Redistribution." American Political Science Review 105(2): 316-36.

Mares, Isabela. 2003. The Politics of Social Risk. New York: Cambridge University Press.

McCarty, Nolan, and Jonas Pontusson. 2009. "The Political Economy of Inequality and Redistribution." In The $\mathrm{Ox}$ ford Handbook of Economic Inequality, ed. Wiemer Salverda, Brian Nolan, and Timothy M. Smeeding. Oxford: Oxford University Press, 665-92.

McCarty, Nolan, Keith T. Poole, and Howard Rosenthal. 2008. Polarized America: The Dance of Ideology and Unequal Riches. Cambridge, MA: MIT Press.

McKelvey, Richard D., and William Zavoina. 1975. "A Statistical Model for the Analysis of Ordinal Level Dependent Variables." Journal of Mathematical Sociology 4: 103-20.

Mehlum, Halvor, Karl Moene, and Ragnar Torvik. 2005. "Crime Induced Poverty Traps.” Journal of Development Economics 77(2): 325-40.

Meltzer, Allan H., and Scott F. Richard. 1981. "A Rational Theory of the Size of Government." Journal of Political Economy 89(5): 914-27.
Milanovic, Branko. 2000. "The Median-Voter Hypothesis, Income Inequality, and Income Redistribution: An Empirical Test with the Required Data." European Journal of Political Economy 16(3): 367-410.

Moene, Kark Ove, and Michael Wallerstein. 2001. "Inequality, Social Insurance and Redistribution." American Political Science Review 95(4): 859-74.

Moene, Karl Ove, and Michael Wallerstein. 2003. "Earnings Inequality and Welfare Spending: A Disaggregated Analysis." World Politics 55(4): 485-516.

Moulton, Brent R. 1990. "An Illustration of a Pitfall in Estimating the Effects of Aggregate Variables on Micro Units." Review of Economics and Statistics: 334-38.

Nelson, Richard R., and Edmund S. Phelps. 1966. "Investment in Humans, Technological Diffusion, and Economic Growth.” American Economic Review 56(2): 69-75.

O'Rand, Angela, and Robert A. Ellis. 1974. "Social Class and Social Time Perspective.” Social Forces 53(1): 53-62.

Page, Benjamin I., and Lawrence Jacobs. 2009. Class War? What Americans Really Think about Economic Inequality. Chicago: University of Chicago Press.

Paulus, Alari, Mitja Čok, Francesco Figari, Péter Hegedüs, Nataša Kump, Orsolya Lelkes, Horacio Levy, Christine Lietz, Silja Lüpsik, Daniela Mantovani, et al. 2009. "The Effects of Taxes and Benefits on Income Distribution in the Enlarged EU." Technical report. EUROMOD Working Article EM8/09.

Pepper, John V. 2002. "Robust Inferences from Random Clustered Samples: An Application Using Data from the Panel Study of Income Dynamics." Economics Letters 75(3): 34145.

Perotti, Roberto. 1996. "Growth, Income Distribution, and Democracy: What the Data Say." Journal of Economic Growth 1(2): 149-87.

Piff, Paul K., Michael W. Kraus, Stéphane Côté, Bonnie Hayden Cheng, and Dacher Keltner. 2010. "Having Less, Giving More: The Influence of Social Class on Prosocial Behavior.” Journal of Personality and Social Psychology 99(5): 77184.

Rehm, Philipp. 2009. "Risks and Redistribution: An IndividualLevel Analysis.” Comparative Political Studies 42(7): 855-81.

Rodriguez, Francisco C. 1999. "Does Distributional Skewness Lead to Redistribution? Evidence from the United States." Economics and Politics 11: 171-99.

Romer, Paul. 1990. "Endogenous Technological Change." Journal of Political Economy 98(5): S71-S102.

Romer, Thomas. 1975. "Individual Welfare, Majority Voting and the Properties of a Linear Income Tax." Journal of Public Economics 7: 163-88.

Roodman, David. 2011. "Estimation Fully Observed Recursive Mixed-Process Models with CMP." Stata Journal 11(2): 159206.

Rubin, Donald. 1987. Multiple Imputation for Nonresponse in Surveys. Hoboken, NJ: Wiley.

Sala-i Martin, Xavier. 1996. "Transfers, Social Safety Nets, and Economic Growth.” IMF Staff Reports 44(1): 81-102.

Shayo, Moses. 2009. "A Model of Social Identity with an Application to Political Economy: Nation, Class, and Redistribution." American Political Science Review 103(2): 147-74. 
Shorrocks, Anthony F. 1980. "The Class of Additively Decomposable Inequality Measures.” Econometrica 48(3): 61325.

Shorrocks, Anthony F. 1984. "Inequality Decomposition by Population Subgroups.” Econometrica 52(6): 1369-85.

Silber, Jacques. 1989. "Factor Components, Population Subgroups and the Computation of the Gini Index of Inequality." Review of Economics and Statistics 71: 107-15.

Stegmueller, Daniel. 2013a. "How Many Countries Do You Need for Multilevel Modeling?" American Journal of Political Science 57(3): 748-61.

Stegmueller, Daniel. 2013b. "Religion and Redistributive Voting in Western Europe." Journal of Politics 75(4): 1064-76.

Vining, Aidan, and David L. Weimer. 2010. “An Assessment of Important Issues Concerning the Application of BenefitCost Analysis to Social Policy." Journal of Benefit-Cost Analysis 1(1): 1-40.

Warr, Mark. 2000. "Fear of Crime in the United States: Avenues for Research and Policy." Criminal Justice 4(4): 451-89.

Western, Bruce. 2006. Punishment and Inequality in America. New York: Russell Sage Foundation.

Wilde, Joachim. 2000. "Identification of Multiple Equation Probit Models with Endogenous Dummy Regressors.” Economics Letters 69(3): 309-12.
Wilson, James Q., and Richard Herrnstein. 1985. Crime and Human Nature. New York: Simon \& Schuster.

Wooldridge, Jeffrey M. 2003. "Cluster-Sample Methods in Applied Econometrics." American Economic Review 93(2): 13338.

Yatchew, Adonis, and Zvi Griliches. 1985. "Specification Error in Probit Models." Review of Economics and Statistics 67(1): 134-39.

\section{Supporting Information}

Additional Supporting Information may be found in the online version of this article at the publisher's website:

S.1 Multiple imputation.

S.2 Distribution of income distance.

S.3 Descriptive statistics.

S.4 Model details.

S.5 Complete tables of model estimates.

S.6 Robustness and placebo tests.

S.7 Classification of Poor and Rich.

S.8 Fixed-effects specifications.

S.9 Income validation against external data 